\title{
Chapter 1 \\ Introduction: Urban Inequality and Segregation in Europe and China
}

\author{
Gwilym Pryce, Yu Chen, and Ya Ping Wang
}

\begin{abstract}
In this chapter, we set out the rationale and key themes for the book. We briefly summarise the broad historical and institutional context, particularly the period of reform in China since 1978, and the background to the hukou household registration system, which has become a key source of segregation and inequality in modern China. We then provide an overview of the book including a synopsis of each chapter and the various links between them. We conclude with a call for further research and evidence-based policy innovation.
\end{abstract}

Keywords $\mathrm{Hukou} \cdot$ Urban inequality $\cdot$ Residential segregation • Equilibrium sorting $\cdot$ Urbanisation $\cdot$ Shantytowns $\cdot$ Regional inequality $\cdot$ Urban villages $\cdot$ Social frontiers

\subsection{Introduction}

Issues of segregation and inequality have shifted to the forefront of political and academic debate in recent years. Piketty's (2014) magnum opus reinvigorated the literature on inequality, elevating the topic from the periphery to the central stage of economics and social science research. At the same time, public concern around issues of segregation and social integration has been heightened as a result of increased migration (Catney 2016; Fingleton et al. 2019; Phillimore 2020). In Europe, it is migration between countries which has been the main cause for concern. In

\footnotetext{
G. Pryce ( $\varangle)$

Sheffield Methods Institute, University of Sheffield, Sheffield, UK

e-mail: g.pryce@sheffield.ac.uk

Y. Chen

School of East Asian Studies, University of Sheffield, Sheffield, UK

e-mail: yu.chen@sheffield.ac.uk
}

Y. P. Wang

School of Social and Political Sciences, University of Glasgow, Glasgow, UK

e-mail: yaping.wang@glasgow.ac.uk 
China, internal migration, particularly from rural to urban areas, has generated both enormous economic growth and significant socio-economic inequalities (Liu 2005).

Unsurprisingly, there has been growing interest in the links between segregation and inequality in terms of both causes and consequences (Tammaru et al. 2016). While the literature on integration/segregation and inequality have traditionally been dominated by European and North American studies, there is burgeoning interest in these issues in the Chinese context. Economic liberalisation, rapid industrial restructuring, the unprecedented growth of cities and internal migration have reshaped the country profoundly. They have also led to increased socio-economic residential segregation and levels of income inequality that now surpass even the most neoliberal Western economies. Migration, segregation and inequality in Chinese cities have increasingly attracted academic attention over the last 20 years (Bian and Logan 1999; Wang 2004; Sicular et al. 2007; Cai et al. 2002; Liu et al. 2018). Nevertheless, the Chinese experience has remained under-represented in mainstream scholarly discussion.

Yet, the story of China's transition is truly remarkable and of global significance. Before 1978, China was known for its strict population movement control, welfareoriented urban management and relative homogeneity in urban living conditions. After more than 40 years of economic reform, China has become a very different country (Wu et al. 2013). On the one hand, China has experienced spectacular success in urban development, which brought significant improvement for a large proportion of urban residents. The emerging middle classes in major cities own modern homes in well-designed new housing estates, many in gated communities. At the same time, however, millions of the urban poor and especially rural-to-urban migrants continue to live in shacks in suburban villages or in basements under glossy apartment buildings. The Chinese urban residential landscape, alongside the wider social, economic and political context, is becoming increasingly complex and polarised. Our understanding of Chinese cities and Chinese society is continually being challenged and reformed through these ongoing processes of change (Huang and Li 2014; Wang 2004; Wu 2004).

Chinese research efforts on these topics have clearly been overwhelmed by the enormity of the migration phenomenon and the complexity of the urbanisation process. Chinese approaches and methods are strongly influenced by the fastchanging social, economic and political environment. Within the hierarchical urban and rural administrative system, there is the distinctive feature of the population registration (hukou) structure, which affects migration patterns directly and the social and economic status of the migrants in destination cities and towns (Knight and Song 1999; Zhang and Tao 2012). Researchers from inside China often find it difficult to communicate these social and political restrictions to the global academic community, and researchers from outside find it difficult to understand the particular nuances of the Chinese social and political context.

The importance of hukou as a driver of segregation and inequality is a theme that permeates Parts II and III of the book so it is worth saying something here about its origins and nature. Hukou can be traced back to ancient Chinese systems of population registration and to 'techniques of social control ... perfected in areas under Kuomintang and Japanese rule' in the early twentieth century (Cheng and Selden 
1994, p. 645). However, hukou in its current form emerged during the 1950s when the communist government sought to introduce a comprehensive system of registration to control population movement and help demarcate eligibility for state-provided goods and services allocated under planned economy principles (Chan 2009).

The household registration system, hukou, emerged from these communist reforms as the,

central institutional mechanism defining the city-countryside relationship and shaping important elements of state-society relations in the People's Republic. Hukou registration not only provided the principal basis for establishing identity, citizenship and proof of official status, it was essential for every aspect of daily life (Cheng and Selden 1994, p. 644).

For every individual, their registration status established their eligibility for employment, housing, clothing, food, education, health and social services. It also led to a bifurcated social system, where the provision of these services in urban areas was essentially 'owned and administered by the state' and urban citizens were 'the state's direct responsibility' (Banister 1987, p. 328). In contrast, the state assumed no such responsibility for these services in rural areas. Cheng and Selden (1994, pp. 644645) explain that 'To the extent that any of these services have been available in the countryside, they have relied on the highly differentiated resources allocated by selfreliant rural communities (villages) or their collective sub-units (production teams)'. Migration, especially that from the countryside to cities, was strictly controlled by the state.

The effect of the hukou system was to create a geographical hierarchy where cities were favoured over rural communities in the allocation of services and economic development. There have been various reforms of the hukou system since the initiation of the economic reforms, partly to adapt to the unprecedented levels of ruralto-urban migration (Chan 2009). However, rural residents who moved to cities to find work, retain their rural hukou status. Without city hukou status, rural migrants had limited rights of access to health care, education, housing and social services. This binary system has become a key driver of urban inequality (Zhao and HowdenChapman 2010), labour market stratification (Chen and Hoy 2008; Chan 2009) and residential segregation (Liu et al. 2018).

The focus of the present book is on the shared and contrasting experiences of segregation and inequality in Europe and China, and a desire to improve dialogue between scholars working in these related fields. Europe's varied cultural and economic history, including the rise and decline of communist planned economies, provides a rich backdrop for the study of segregation and inequality. What have we learned from the European experience of segregation, integration and inequality, and what insights can be gleaned to inform the bourgeoning interest in these issues in the Chinese context? How is China different, both in terms of the nature and consequences of segregation and inequality, and what are the implications for future research and policy? What forms do inequalities take in modern China? To what extent are they the natural outcome of an emerging meritocracy, and to what extent are they the byproduct of entrenched institutional inequities and bureaucratic failures? Has the process of reform and regeneration itself generated inequalities in housing, exposure 
to pollution, and access to public services? These are the questions at the heart of this collected volume.

We believe this book offers a timely contribution to scholarship as China's significance increases globally and its policy focus shifts towards improving the quality of life rather than economic growth. To this end, we have drawn together leading researchers from Europe and China to reflect on the most relevant developments in research and policy, and to open up new avenues of scholarly conversation. The book also aims to provide guidance on future directions for policymakers and researchers in this increasingly important field.

\subsection{Overview}

The remainder of the book is organised into three parts:

- Part I: Lessons from Europe.

- Part II: Urban Inequality and Integration in China

- Part III: Future Directions for Research and Policy

We shall now summarise each of these sections in turn.

\subsubsection{Part I: Lessons from Europe}

In Part I, we review the European/Western experience in terms of the underlying social and economic drivers of segregation and inequality. The section begins with Chap. 2 by Aneta Piekut, which offers a review of European research on spatial segregation. Piekut highlights the key theoretical insights that explain why, in the absence of legally enforced apartheid, Western cities nevertheless become segregated along ethnic, religious and social divides. This is an interdisciplinary review spanning urban studies, sociology, psychology, spatial and human geography, providing a holistic understanding of the underlying mechanisms.

Chapter 3 by Tiit Tammaru and colleagues complements Piekut's survey of the literature by providing an empirical overview of trends in socio-economic residential segregation in European cities. They also investigate the specific hypothesis that income inequality is a major driver of residential segregation. Drawing on data for the cities of Amsterdam, Athens, Budapest, Helsinki, London, Madrid, Milan, Oslo, Prague, Riga, Tallinn, Stockholm and Vilnius, they find that changes in segregation levels tend to follow changes in inequality with a 10-year time lag. Although the analysis is preliminary, it nevertheless has important implications for the long-term trajectory of segregation for both European and Chinese cities if income inequality continues to rise. 


\subsubsection{Part II: Urban Inequality and Integration in China}

Part II of the book starts with an overview by Yu Chen and Jie Chen of research on segregation in Chinese cities. Before the reforms in 1978, urban segregation had essentially been eradicated as a result of the socialist work-unit systems and the non-market allocation of housing. Since then, cities have become increasingly segregated as a result of a complex combination of institutional factors such as the hukou household registration system, massive rural-urban migration, economic and spatial restructuring, and market forces.

These themes, and China's recent policy responses, are explored in depth by Wei Houkai and Su Hongjian in Chap. 5. The authors document the processes and scale of urbanisation and rural-to-urban migration since the start of the reform era and the major shift in policy emphasis since 2014 towards quality improvement. This new agendum has led to growing recognition among policymakers that urban and rural poverty poses a major challenge to economic and social development, leading to a significant nationwide poverty reduction initiative. The authors offer a programme of reform that includes reform of the hukou system, urban-rural integration and coordinated poverty management.

One of the distinct features of China's urbanisation is the emergence of urban villages. As cities expanded, villages close to the urban periphery were absorbed and villagers converted their homes into rental properties to take advantage of the growing demand for accommodation from rural migrants. Many of these urban villages were redeveloped by city planners, and villagers were relocated to new housing. In Chap. 6, Ya Ping Wang uses a village in Beijing as a case study for this historical development, highlighting the associated benefits, challenges, and inequalities. A major theme once again is the persistent problem of the hukou system: 'the new property rights for the replacement flats confer no additional rights of citizenship for the relocated villagers who remain "second class" citizens within Chinese cities'.

In Chap. 7, Guoqing Li considers the related issue of shantytown renovation. The chapter provides a comparative study of four models of shantytown reconstruction, charting their emergence as new forms of urban community. Guoquing Li highlights the problems posed by shantytown renovation and the policy reforms needed to improve their integration into wider society.

In Chap. 8, Jingjing Shan and colleagues encourage us to step back from these specific examples of urban development to consider the wider system-driven disparities across the whole country. Inequalities have arisen as a result of China's rapid urban expansion and the persistant binary nature of the hukou registration system. The authors provide a detailed and comprehensive attempt to quantify inequalities in access to public services between the local urban population and migrant workers. The chapter considers inequalities between urban and rural areas, and also those within urban areas, and between regions. They find evidence of large inequalities at multiple geographical levels and argue for a programme of reforms to reduce inequalities in the geographical provision of education and medical health services, particularly in rural areas. 
The final contribution in Part II is by Yeqiang Wang and Xin Dong (Chap. 9) which focuses on the problem of insecure and poor quality housing for migrant workers in China's cities. They provide a detailed account of the large discrepancies in levels of access to good quality accommodation between migrants from rural areas and the established urban population. These inequalities are exacerbated by inherited forms of residential registration that adversely affect rural migrants settling in towns and cities. The situation is worsened by land-use regulations that restrict the construction of collective dormitories for rural migrant workers. Policy responses over the past 20 years are evaluated, and recommendations for future policy development are proposed to improve housing conditions, including reform of land use regulations and improved property rights for migrants.

\subsubsection{Part III: Future Directions}

The third and final section of the book reflects on areas for future research and policy development with respect to urban segregation and inequality in China. Given the content and limitations of extant European research on integration and inequality, and the unique context of Chinese social and economic development, what should be the focus of future research and policy development in these fields? The final six chapters of the book suggest ways forward. They highlight elements of the Western literature that are most apposite to the Chinese context, and also the important differences in Chinese culture and society that need to be taken into account. Both aspects potentially open up new ways of thinking about segregation and inequality. There is a strong methodological theme to these chapters, drawing on cutting-edge ideas and methods to illuminate new avenues for inquiry.

The first of these chapters is Chap. 10 by David Manley, Gwilym Owen, Hui Song and Bifeng Wang. The authors draw on one of the most important innovations in segregation research in recent decades, the application of multi-level modelling techniques to the measurement of segregation. One of the limitations of traditional approaches is that they tend to be uni-dimensional. For example, they struggle to take into account the extent to which apparent segregation in one dimension (such as ethnicity) is in fact explained by segregation in another dimension (such as income). This is an important limitation as particular ethnic groups may have lower than average income. As a result, their geographic separation from other and wealthier ethnic groups may have nothing to do with a mutual aversion to living near people of different ethnicity, but simply due to the geographical concentration of affordable housing. The new generation of multilevel modelling approaches potentially overcomes this limitation, while also allowing researchers to distinguish between segregation occurring at different spatial scales. The authors of Chap. 10 explain the theoretical basis for this new approach and offer one of the first applications of the method to Chinese data. They use the model to estimate the segregation of different ethnic groups and of migrants versus non-migrants in Shijiazhuang, the capital city 
of Hebei Province. The chapter concludes with suggestions for future research and policy development.

Residential segregation is a very important aspect of the separation of groups in society but is, by no means, the only form segregation takes. This is very clearly highlighted in Chap. 11, which considers segregation in social relations between care workers in Shanghai. The authors, Wenjing Zhang and Yiming Wang, use Social Network Analysis to conceptualise, visualise and explain friendships between workers in a care home. An important innovation is to complement the quantitative Social Network Analysis with qualitative interviews. Their approach not only reveals the extent of relationship segregation between migrant worker carers and those born locally but also shows how this new mixed-methods approach has the potential to transform and enrich future application network analysis in China and elsewhere.

Chapter 12 provides what is probably the first application in China of an 'equilibrium sorting model'. This sophisticated combination of economic theory and statistical analysis has become one of the most robust ways to model 'residential sorting' the tendency for the housing market to group people by their characteristics, income and preferences. Such models have a wide range of applications including the estimation of people's willingness to pay for intangible amenities such as clean air, low crime, leisure facilities, green space, access to good schools and employment. The authors argue that being able to place a monetary value on these important drivers of human welfare will be essential for China to achieve its new priority goal of improving quality of life, as opposed to focusing exclusively on economic growth. One of the key methodological findings of this pioneering study is that it highlights the importance of incorporating mobility costs when using equilibrium sorting models to estimate the willingness to pay.

Further methodological developments are highlighted in Chap. 13 in the context of a particular form of residential segregation that arises from the way communities border. Authors Ivana Křížková, Meng Le Zhang, Dan Olner and Gwilym Pryce explore the concept of 'social frontiers' (Dean et al. 2019) — the existence of sharp spatial divisions in the residential make-up of adjacent communities that take on symbolic and territorial meaning. Whilst some social frontiers are marked by physical barriers, such as the 'peace walls' ${ }^{1}$ in Belfast, many others are effectively invisible to researchers. Křížková and colleagues explain why these frontiers are considered an especially problematic form of residential segregation and demonstrate a practical empirical approach to their estimation. The authors use data on a post-socialist country, Czechia. This makes the study especially salient to the modern Chinese context with similar challenges associated with the deconstruction of historical institutions from the communist era, combined with new problems arising from market liberalisation.

Whilst most of the chapters in Part III focus on innovations in segregation research, in Chap. 14, Gwilym Owen and colleagues remind us of the need for methodological robustness and innovation with respect to the measurement of poverty and inequality. In order for China's poverty alleviation programme to be effective, it needs to find

\footnotetext{
${ }^{1}$ Security walls erected to keep rival communities apart.
} 
reliable ways of quantifying and monitoring urban deprivation. Crucially, the burden of poverty is not just about lack of income, though this is often the key driver. Deprived households experience privations in a whole range of factors-including poor health, inadequate housing, limited access to public services, employment and education, and high levels of crime and environmental pollution. China's new public policy emphasis on improving quality of life leads, unsurprisingly, to the need to target resources effectively. To this end, Chinese researchers are finding ways to estimate Indices of Multiple Deprivation (IMDs) to highlight and address geographical inequalities. Originally developed in the UK, IMDs offer a powerful tool to capture multiple layers of disadvantage at the neighbourhood level. Unfortunately, data limitations pose real challenges for computing reliable IMDs in China. These problems have been made worse by methodological weaknesses in some of the recent Chinese applications. Gwilym Owen and colleagues 'seek to bring direction and conceptual rigour to this nascent literature by establishing a set of core principles for IMD estimation that are relevant and feasible in the Chinese context'. They demonstrate these principles with an empirical application to census data on Shijiazhuang, the capital city of Hebei province. Their four-step approach provides a template for provincial and city-region governments throughout China to monitor and address deprivation.

In the concluding chapter (Chap. 15), Gwilym Pryce attempts to synthesise the findings of the book, identify areas where more research is needed and highlight opportunities for innovation both in research methods and policy development. A key area for future research is the need to shift from a static understanding of segregation towards a dynamic one. This is especially important in the Chinese context where so much remains in flux and urban change continues at an astonishing pace in many cities. In line with this dynamic perspective, Pryce then considers the way in which inequality and segregation are related, drawing on the recent work of Galster and Sharkey (2017). The chapter goes on to highlight the relational and psychological impacts of inequality and segregation, which need to be included in the calculus of social and economic policy. The chapter concludes by reflecting on the implications of the Causal Revolution in social science research methods. These have the potential to transform the way urban policy in China is developed and evaluated when combined with these other proposed directions in future research.

\subsection{Conclusion}

Our goal in this collected volume is to bring important research on Chinese segregation and inequality to an international audience and further the dialogue between European and Chinese scholars in particular. We hope you be both intellectually stimulated by this collection of essays, and also inspired to find new and effective ways of alleviating the social and economic challenges facing the people of China.

Acknowledgements The book and chapters have benefitted from research funding support from the Chinese Academy of Social Sciences (CASS), the Institute of Urban and Environmental Studies 
at CASS, the Hebei Statistical Bureau, and several research grants funded by the Economic and Social Research Council (ESRC). These include the 'ESRC/CASS Urban Transformations-Urban Development, Migration, Segregation and Inequality' project (Grant Reference: ES/N007603/1), the ESRC Understanding Inequalities project (Grant Reference ES/P009301/1) and the ESRC Global Challenges Research Fund: Dynamics of Health and Environmental Inequalities in Hebei Province, China (Grant Reference: ES/P003567/1).

\section{References}

Banister J (1987) China's changing population. Stanford University Press, Stanford, p 328

Bian Y, Logan JR (1996) Market transition and the persistence of power: the changing stratification system in urban China. Am Sociol Rev 739-758.

Cai F, Wang D, Du Y (2002) Regional disparity and economic growth in China: the impact of labor market distortions. China Econ Rev 13(2-3):19-212

Catney G (2016) Britain is becoming more diverse, not more segregated, the Conversation. https:// theconversation.com/britain-is-becoming-more-diverse-not-more-segregated-68610t

Chan KW (2009) The Chinese hukou system at 50. Eurasian Geogr Econ 50:197-221

Cheng T, Selden M (1994) The origins and social consequences of China's hukou system. China Q (139):644-668

Chen Y, Hoy C (2008) Rural migrants, urban migrants and local workers in Shanghai: segmented or competitive labour markets? Built Environ 34(4):499-516

Dean N, Dong G, Piekut A, Pryce G (2019) Frontiers in residential segregation: understanding neighbourhood boundaries and their impacts. Tijdschr Voor Econ En Soc Geogr 110(3):271-288

Fingleton B, Olner D, Pryce G (2019) Estimating the local employment impacts of immigration: a dynamic spatial panel model. Urban Stud 57(13):2646-2662.

Galster G, Sharkey P (2017) Spatial foundations of inequality: A conceptual model and empirical overview. RSF: Russell Sage Found J Soc Sci 3(2):1-33

Huang Y, Li SM (eds) (2014). Housing inequality in Chinese cities. Routledge, Abingdon

Knight J, Song L (1999) The rural-urban divide: economic disparities and interactions in China. OUP Catalogue

Liu Z (2005) Institution and inequality: the hukou system in China. J Comp Econ 33(1):133-157

Liu L, Huang Y, Zhang W (2018)Residential segregation and perceptions of social integration in Shanghai, China. Urban Stud 55(7):1484-1503

Phillimore J (2020). Refugee-integration-opportunity structures: shifting the focus from refugees to context. J Refug Stud

Piketty T (2014). Capital in the twenty-first century. Belknap of Harvard UP, Cambridge, MA, p 452

Sicular T, Ximing Y, Gustafsson B, Shi L (2007) The urban-rural income gap and inequality in China. Rev Income Wealth 53(1):93-126

Tammaru T, Marcińczak S, van Ham M, \& Musterd S (2016). Socio-economic segregation in European capital cities: east meets west (Regions and Cities). Routledge, London

Wang YP 2004 Urban poverty, housing and social change in China, Routledge, Abingdon

$\mathrm{Wu} \mathrm{F}$ (2004) Urban poverty and marginalization under market transition: the case of Chinese cities. Int J Urban Reg Res 28(2):401-423

Wu W, Gaubatz PR, für Stadtgeographie P (2013) The Chinese city. Routledge, New York

Zhang L, Tao L (2012) Barriers to the acquisition of urban hukou in Chinese cities. Environ Plan A 44(12):2883-2900

Zhao P, Howden-Chapman P (2010) Social inequalities in mobility: the impact of the hukou system on migrants' job accessibility and commuting costs in Beijing. Int Dev Plan Rev 32(3/4):363 
Open Access This chapter is licensed under the terms of the Creative Commons Attribution 4.0 International License (http://creativecommons.org/licenses/by/4.0/), which permits use, sharing, adaptation, distribution and reproduction in any medium or format, as long as you give appropriate credit to the original author(s) and the source, provide a link to the Creative Commons license and indicate if changes were made.

The images or other third party material in this chapter are included in the chapter's Creative Commons license, unless indicated otherwise in a credit line to the material. If material is not included in the chapter's Creative Commons license and your intended use is not permitted by statutory regulation or exceeds the permitted use, you will need to obtain permission directly from the copyright holder.

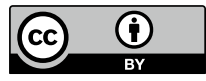

